\title{
Towards a more expansive understanding of equitable forms of organisation
}

\author{
Margaret Walshaw ${ }^{1}$
}

Published online: 30 April 2015

(c) Springer Science+Business Media Dordrecht 2015

Over the past three decades, we have witnessed a growing interest in understanding and responding to inequitable mathematical experiences. The engagement is often aligned with a concern for students with "outsider" status-those students who are bracketed out from the mainstream student experience of mathematics. As many are aware, the interest has arisen, in part, by observations of the changing nature of our mathematics classrooms that increasingly cater for diverse groups of learners. Reflections on student cultural and linguistic diversity and rising socioeconomic differentials have put advocacy for students who are located on the "wrong" side of the social divide high on the agenda. As a result, the social justice goal to enhance student inclusion and to halt systemic underachievement amongst specific groups has sparked new kinds of research projects and initiated a wide range of student-centred interventions.

But surely the social justice project is not simply confined to an investigation of students' experiences. In the spirit of a more expansive understanding about equitable arrangements within mathematics education, we might interrogate the conditions, experienced by prospective, novice and experienced teachers which appear to deny them any sense of agency while working within institutional hierarchies. Like it or not, some mathematics teachers, irrespective of level of experience, confront challenges and problems, simply from being caught up in changes within the wider educational apparatus. An analysis of these contexts is timely. Such an analysis would represent a broader form of social critique. It would signal a commitment to engage in political struggle over the meaning of mathematics teaching and mathematics teacher education itself.

An interrogation, like this, might ask, for example, what are the tensions experienced by teachers when focused on understanding and implementing new policy directives but without the benefit of support from senior mathematics teachers or from professional learning opportunities? Or we might ask: how do teachers negotiate contradictory advice

Margaret Walshaw

m.a.walshaw@massey.ac.nz

1 Palmerston North, New Zealand 
about what new policy ideas mean? An analysis of these contexts involves an understanding the rollercoaster of events and the emotions they animate. It requires mapping out how constraints and conflict become lived as individual dilemmas. What is important for the social justice project is that rich ground for talking about ethical practical action will emerge. That is because once we start looking at day-to-day interrelations and at how intersubjective negotiations take shape within the institutions of mathematics teacher education, we can then begin to understand what might need to happen to initiate change. Such an interrogation would become a significant driver towards more equitable forms of organisation, pointing to what we might do for teachers to produce more equitable outcomes.

While the articles in this issue of JMTE are all driven by an implicit objective to produce equitable outcomes for teachers, their starting point is with support and opportunities to learn. In "Examining teachers' understanding of the mathematical learning progression through vertical articulation during Lesson Study," Jennifer Suh and Padmanabhan Seshaiyer describe a six-month professional learning opportunity centred on algebraic concepts across grade levels. The project was designed to assist teachers to come to a deeper understanding of the learning progression and the sequence of concepts within that progression, as set out within a national document. The cross-grades aspect was built into the design to allow teachers to become familiar with the concepts at multiple levels, on the basis of the understanding that when teachers expand their algebraic knowledge, they are able to make valuable links with algebraic knowledge above and below their teaching grade level.

A vertical school-based Lesson study, involving six teachers across three grade levels, followed a shorter content-focused programme. The case study teachers investigated the mathematical content applicable to a number of levels and selected a rich algebraic task. Planning for teaching the task addressed issues relating to student grade level knowledge, prior pedagogical strategies that might be productive, identifiable problems and the scaffolding required, and an appropriate assessment task. Each teacher customised the task to suit the grade level of students being taught. The data set for the project included video clips from the research lessons, student work, teacher reflections, and researchers' notes. From the Lesson Study teaching of the lessons, an understanding became clear in relation to what students were capable of achieving at the various levels. The authors found that the multigrade interactions were instrumental in pushing discussion about and teachers' knowledge of and thinking across the learning progression, allowing teachers to appreciate the coherence within the progression's structure.

The second article in this issue is also focused on the process of interaction. In "Increasing awareness of practice through interaction across communities: The lived experiences of a mathematician and mathematics teacher educator," Sarah K. Bleiler describes the interactions between and the lived experiences of a mathematician and a mathematics teacher educator involved in a teaching collaboration. The project was developed in response to a lack of attention to shared teaching arrangements and, in particular, to the lack of attention to the dynamics of such collaborations within earlier work. The context for this research was a team-taught mathematics content and mathematics methods course, namely a Geometry course and a Senior High School Mathematics Teaching Course designed for prospective secondary mathematics teachers. Phenomenology provided a framework for the analysis of the collaborative process.

The two key participants were selected on the basis of their seemingly polarised perspectives of mathematics teaching and learning and on the basis of their different work experiences. One-on-one and paired interviews constituted the principal data sources. 
Other data sources emerged from field notes, video recording of classes, audio recordings of planning sessions, and a student questionnaire. Setting the scene for the analysis was the positioning of the mathematician and the mathematics educator. Engaged in markedly different communities of practice, both revealed allegiances to different "joint enterprises." However they were willing, to greater and lesser extent, to negotiate these ways of being and ways of doing things in their planning and teaching of the course. Their productive negotiation led to an enhanced understanding of themselves as teachers and an enhanced understanding of the professional development opportunity arising from the project. Both recognised the importance of stepping outside the familiarity of their respective communities as a means to heightened professional learning.

Negotiation and responsiveness are at the heart of the third article in this issue. In "Student and teacher interventions: A framework for analysing mathematical discourse in the classroom," Ove Gunnar Drageset reports on the development of a framework for analysing discourse on a turn-by-turn basis. The turn-by-turn approach was selected with the primary purpose of developing concepts to describe the discourse taking place between students and teacher in the classroom. After explaining the benefits and limitations of coding frameworks in use within mathematics education, Drageset then employed conversation analysis to develop codes for investigating interaction on its own terms, and, in particular, to demonstrate the effects of single turn taking on one teacher's practice. The setting for the research was Norway and from an initial large-scale questionnaire, two knowledge constructs and two belief constructs were developed.

Employing these constructs in the main component of the research, the researcher used five upper primary (elementary) school teachers' classrooms as contexts for studying teacher-student discourse during a week-long series of lessons relating to fractions. In a process that involved careful analysis of individual interventions, separately for students and teacher, simultaneously nested within the wider discourse, categories were developed iteratively and a framework was then constructed. Two circular patterns emerged. The most frequent interactions were teacher-led responses which preceded focusing actions. The next most frequent interactions involved unexplained answers which preceded progressing actions. These actions involved teacher requests for more information or a demonstration of important steps in the solution of a problem. The framework used by the authors provided a window into the content of the discourse between teacher and students to determine whether or not mathematical argumentation and critique are fostered. Typically, however, in this video study, teachers did not explore students' thinking nor did they facilitate debates.

Our final article in this issue is focused on connections between professional learning and practice. In "Tracing professional development to practice: Connection making and content knowledge in one teacher's experience," Chandra Hawley Orrill and Julie M. Kittleson explore the links between what one teacher learns about connection making within a professional development initiative and the ways in which that learning is put into practice in a middle school classroom. It is argued that making connections between ideas contributes to students' conceptual development. As a corollary, teaching disconnected facts demonstrates a lack of understanding of the coherence of mathematical ideas. In the analysis, the researchers took a grounded-theory approach for the development of a framework appropriate for explaining discussion facilitation, representation use, multiple approach promotion, and learning scaffolds.

The teacher involved in the project had participated in a 14-week professional learning experience, exploring fractions. Underwriting the initiative were two goals: (1) teachers would engage in connection making and (2) pedagogical strategies to support connection 
making would be modelled. Data on which the report draws were taken from video recordings of the professional development (PD) in which proportional reasoning was explored. The report also drew on video recordings from the teacher's classroom and written teacher reflections and an interview complemented the main data set. Orrill and Kittleson found that while the teacher was able to mirror the pedagogical approaches used in PD within her own classroom, she did not have a clear mathematical understanding of the task in which she had engaged and which she later taught in her class. Her limited mathematical knowledge prevented her from making sound mathematical connections. The authors emphasise that, on the basis of these findings, knowledge creation resources in PD do not always transfer to the classroom.

All the authors in this issue of the journal are able to look deeply into teachers' practice. By doing that, they allow us to think differently about constructing practices that are responsive and appropriate to specific individuals and for specific settings. Such analyses allow us to create a space where new possibilities might be envisioned. 